This document was prepared in conjunction with work accomplished under Contract No. DE-AC09-96SR18500 with the U.S. Department of Energy.

This work was prepared under an agreement with and funded by the U.S. Government. Neither the U. S. Government or its employees, nor any of its contractors, subcontractors or their employees, makes any express or implied: 1 . warranty or assumes any legal liability for the accuracy, completeness, or for the use or results of such use of any information, product, or process disclosed; or 2 . representation that such use or results of such use would not infringe privately owned rights; or 3 . endorsement or recommendation of any specifically identified commercial product, process, or service. Any views and opinions of authors expressed in this work do not necessarily state or reflect those of the United States Government, or its contractors, or subcontractors. 


\section{MODEL 9975 SHIPPING PACKAGE FABRICATION PROBLEMS AND SOLUTIONS}

\author{
Cecil G. May/Savannah River National \\ Laboratory
}

\begin{abstract}
The Model 9975 Shipping Package is the latest in a series (9965, 9968, etc.) of radioactive material shipping packages that have been the mainstay for shipping radioactive materials for several years. The double containment vessels are relatively simple designs using pipe and pipe cap in conjunction with the Chalfont closure to provide a leak-tight vessel. The fabrication appears simple in nature, but the history of fabrication tells us there are pitfalls in the different fabrication methods and sequences. This paper will review the problems that have arisen during fabrication and precautions that should be taken to meet specifications and tolerances. The problems and precautions can also be applied to the Models 9977 and 9978 Shipping Packages.
\end{abstract}

\section{INTRODUCTION}

The 9975 Shipping Package ${ }^{1}$ is a Type B radioactive material shipping package that was a continuation of the 9965/9968 family of packages designed and used in the 1970's to early 1990's. The 9965/9968 packages had double containment vessels using Chalfant closures designed to the ASME Section VIII Code. The 9975 package included several refinements of the 9968 to include a containment vessel design based on the ASME Section III Code ${ }^{2}$.

The 9975 packaging assembly includes an outer 35-gallon stainless steel drum and lid with a bolted closure. Inside the drum is a cylindrical stainless steel liner surrounded by lead shielding that holds the primary containment vessel (PCV) and secondary containment vessel (SCV). The shielding body is centered in the drum with Celotex insulation filling the space between the shielding body and drum shell. Figure 1 shows a cutaway of the 9975 with the components identified.

\author{
Dr. Allen C. Smith/Savannah River National \\ Laboratory
}

The 9975 containment vessels are simple pipe vessels consisting of a pipe cap, Schedule 40 pipe, and a stayed head, all fabricated from Type 304L austentic stainless steel. A cone seal plug and cone seal nut assembly that screws into the stayed head provides closures for both containment vessels. The containment vessels were designed to be a simple fabrication consisting of two circumferential full fusion welds attaching the pipe cap and stayed head to the pipe section and a fillet weld attaching a footing to the pipe cap. The machining of the Chalfant closure must be exact, but is well within the capabilities of commercial machines.

More than 40009975 Packages have been fabricated since 1998 for use by the DOE complex. During the initial learning curve, several problems arose. This paper will identify those problems and discuss the solutions and also include changes and issues that have occurred during the use of the 9975 package.

\section{NOMENCLATURE}

Chalfant Containment vessel design developed by Gordon Chalfant of Savannah River Site

CV Containment Vessel

DOE US Department of Energy

SARP Safety Analysis Report for Packaging

PCV Primary Containment Vessel

SCV Secondary Containment Vessel

\section{DRUM OVERPACK}

Lid/Drum Flange Hole Misalignment 
During normal use of the 9975 package, misalignment of the bolt holes of the drum lid and drum body flange was discovered. In some cases the holes of the lid were made oblong to allow the bolts to mate with the holes and nuts of the drum flange. This problem can be caused by weld distortion if the holes are drilled prior to welding the flange to the drum shell. If the holes of the flange and lid are drilled separately, the holes may not match due to machining tolerances. A solution is to drill the holes while the lid and flange are mated together after welding, allowing the drilling of one set of holes for both parts. Additional attention to the welding technique when welding the flange to the drum liner will decrease distortion contributing to misalignment.

\section{Final Total Weight}

The final weight of the fabricated packaging is critical because the 9975 package is tested and approved based on the maximum weight of the package. The specified maximum empty package weight (370 lbs) in the 9975 Safety Analysis Report for Packaging (SARP) is very close to the sum of the theoretical weights of individual pieces. When the weight of the empty package is over the specified maximum empty weight, the weight of the contents for shipment must be reduced which may increase the number of packages and shipments.

The maximum weight of the empty fabricated packaging was based on the sum of the nominal weights of the components. When materials used in the fabrication of individual components run on the maximum side of tolerances, the increased weight may overrun the maximum weight. The vendor must consider this possibility and maintain proper weight control during fabrication.

The Celotex material is a large part of the drum overpack and contributes significantly affects the overall weight. Two issues with Celotex effect the total weight: 1) the glue used to glue the layers together; and , 2) the moisture content.

Celotex materials are made at the factory in sheets 0.5-inch in thickness. The glue used at the factory is a soybean based glue and weighs less than the Elmer's glue required by the drawings to laminate layer of Celotex together. Purchasing the Celetox in sheets laminated at the factory using soybean glue reduces the layers of Elmer's glue if laminated by the vendor. Also, the Elmer's glue should be used sparingly to avoid excessive glue and weight.

When Celotex material is stored, it has the tendency to absorb moisture from the atmosphere. If material is left in the outdoors where humidity is high, the moisture pick-up will add to the overall weight of the Celotex. Vendors may not have control over storage of material before receiving, but should store the material in a controlled environment at their facility.

\section{CONTAINMENT VESSELS}

\author{
End Cap Machining
}

The use of commercial pipe caps and pipe in the design of the 9975 and earlier containment vessels was intended to make the fabrication of the CV's simple and straight forward. Manual welding of the pipe cap to pipe and pipe to the stayed head can overcome the misalignment that comes from normal tolerances in ovality and thicknesses of commercial pipe and pipe caps. However, during mass production using machine welding, misalignment in the circumferential weld joints of the CV body becomes a bigger issue. Preparation of even weld joint bevels and lands is difficult when ovality is present and machine welding sometimes cannot make adjustments for this misalignment.

A method of reducing misalignment is the machining of heavy wall pipe caps' internal diameters (ID) to produce stub ends with round ends and consistent weld bevels. If the machined area extends into the knuckle area of the pipe cap, minimum wall thickness may be violated.

Two methods of overcoming this problem is: 1) machine a transition bevel from the machined ID of the stub end and contour the internal surface of the pipe cap in the knuckle area to accept the gage representing the 3013 contents; and, 2) start with a heavy wall pipe cap and machine the entire internal cavity to the desired thickness.

Both methods may be successful: however, the wall thickness must be verified in either case. When machining the entire internal surface, the final surface must meet the contour requirements of ASME B16.9, Factory-Made Wrought Buttwelding Fittings.

\section{Leak Test Port Hole/Cone Seal Scratches}

The cone seal plug of the 9975 closure includes a circular cone machined from Type 304L stainless steel rod. The edge of the cone is machined 10 degrees to form the cone edge. Two grooves are machined into the coned edge for holding two O-rings. The upper O-ring provides the containment boundary of the $\mathrm{CV}$ and along with the lower O-ring provides an annulus space for leak testing the closure. A horizontal 0.094-inch diameter port hole connects the annulus space to a vertical test port in the center of the cone. See Figure 2.

There have been instances where the edge of the hole opening into the annulus space was not sufficiently deburred. When the cone seal was closed, the burrs scratched the matching coned surface of the stayed head.

The cone seal plug was first sealed during the hydostatic test. At that time there probably was sufficient Krytox ${ }^{\circledR}$ grease and 
silicon high vacuum grease present on the surfaces to mask the scratches caused by the burrs. The scratches were not detected until later when the CV's were cleaned and loaded for shipment. Although the scratches have not caused leaks in the closure, they are obvious when the surfaces are cleaned and have caused concern of the users. The scratches found to date have been removed using 600 to 800 grit sand paper.

During fabrication, the hole opening is a special concern and increased attention by both the fabricator and inspector is necessary to assure proper deburring of the hole edge after drilling and machining.

\section{Krytox $^{\underline{Q}} \underline{\text { Grease }}$}

The CV's closure consists of a cone seal plug with O-rings and a cone seal nut. The cone seal nut's outer edge is threaded and is screwed into the CV body applying a downward sealing force on the cone seal plug. The threads and bearing surface between the cone seal plug and cone seal nut are lubricated with Krytox ${ }^{\circledR}$ grease. A reference point for tightening the coneseal nut is established by applying the prescribed torque to the cone seal nut (without the O-rings installed on the cone seal plug) and then scribing a continuous radial line across the tops of the cone seal nut and the vessel body. When loading and preparing a 9975 for shipment, the radial line on the cone seal nut must line up to within 1 inch of the line on the vessel body to assure a leak-tight closure. See Figure 3.

There have been cases where new packages were closed by users and, after applying the proper torque, the lines were outside the allowed tolerance. It is suspected that an excessive amount of grease was used in the assembly at the vendor facility and over time the excess grease seeped from the assembly leaving a gap between the nut and plug. The larger gap caused the scribe lines to be out of alignment when the cone seal nut was torqued during operation.

By using the $\operatorname{Krytox}^{\circledR}$ grease sparingly when assembling the closure, the alignment marks should be within tolerance.

\section{Materials Compatibility}

Early in the development of the Chalfant containment vessels, the cone seal nuts, which were made from Type 304 stainless steel, were prone to galling with the matching Type 304 containment vessel body. The material specification was changed to Nitronic 60 and the use of Krytox lubricant was specified. These measures have prevented recurrence of the galling problem.

VibroEtch of Machined Surfaces
During an interruption in manufacture of some of the 9975 packages cone seal nuts which had been completed but not assembled with other components were marked with tracking numbers to maintain their identity. These numbers were vibroetched on the bottom of the cone seal nut. The surface which was marked is the interface with the cone seal plug, and when the assembly was torqued, the raised metal generated by the vibroetch process scratched the matching cone seal plug surface and was embossed into the surface. The surfaces in question have a $65 \mathrm{rms}$ finish, which was defaced by the vibroetching, and the subsequent assembly of the components. Corrective action has required removal of raised ridges and smoothing scratches by hand polishing with No. 600 emery paper.

Mating surfaces must not be vibroetched or marked in any manner that causes raised ridges or scratches.

\section{OVERALL PACKAGE - COMMENTS/PROBLEMS}

\section{Lead Carbonate Formation}

The Surveillance Program for 9975 packages in long term storage revealed formation of a white deposit on the lead shield assembly of a few units. Subsequent chemical analysis revealed that the material was lead carbonate $(\mathrm{Pb}(\mathrm{HCO}) \mathrm{x})$. Formation of lead carbonate takes place in the presence of acetic acid vapor. Screening tests indicate that the Polyvinylacetate adhesive used for assembly of the Celotex overpack is the likely source of the acetic acid. Formation of the deposit is inhibited by allowing ample cure time between assembly of the overpack insert and installation of it into the drum. To address this in a more comprehensive manner, the lead shield assembly has been redesigned to incorporate an outer stainless steel enclosure, so that the lead is encapsulated.

\section{Celotex Beetles}

Two 9975's being prepared for loading were found to be infested with small insects. These were subsequently identified as "Drugstore Beetles", scientific name Stegobium Paniceum (Coleoptera Anobiidae). The source of the beetles or the time in the life of the package when they took residence in the Celotex overpack has not been conclusively determined. Similar infestations have not been found in any other packages. Although the channels made by the beetles are small and dispersed, studies are underway to determine their effects on the structure of the Celtoex and to develop strategies for fumigate any affected packages.

\section{DISCLAIMER}

This document was prepared in conjunction with work accomplished under Contract No. DE-AC09-96SR18500 with 
the U. S. Department of Energy. DISCLAIMER This report was prepared as an account of work sponsored by an agency of the United States Government. Neither the United States Government nor any agency thereof, nor any of their employees, nor any of their contractors, subcontractors or their employees, makes any warranty, express or implied, or assumes any legal liability or responsibility for the accuracy, completeness, or any third party's use or the results of such use of any information, apparatus, product, or process disclosed, or represents that its use would not infringe privately owned rights. Reference herein to any specific commercial product, process, or service by trade name, trademark, manufacturer, or otherwise, does not necessarily constitute or imply its endorsement, recommendation, or favoring by the United States Government or any agency thereof or its contractors or subcontractors. The views and opinions of authors expressed herein do not necessarily state or reflect those of the United States Government or any agency thereof.

\section{ACKNOWLEDGMENTS}

The authors would like to thank Julio Pardo, Paul Blanton, Glenn Abramczyk, Dan Leduc, Lawrence Gelder, Bradley Loftin, and Joseph Murphy of the Savannah River Packaging Technology group for their contributions in the compilation of lessons learned during previous 9975 package fabrication.

\section{REFERENCES}

1. Model 9975 Safety Analysis Report for Packaging, SSARP-G-2003, Revision 0, January 2008

2. ASME Boiler and Pressure Vessel Code, Section III, Rules for Construction of Nuclear Power Plant Components, Division 1, Subsection NB, American Society of Mechanical Engineers, New York, NY (1992 and 2004 Editions) 


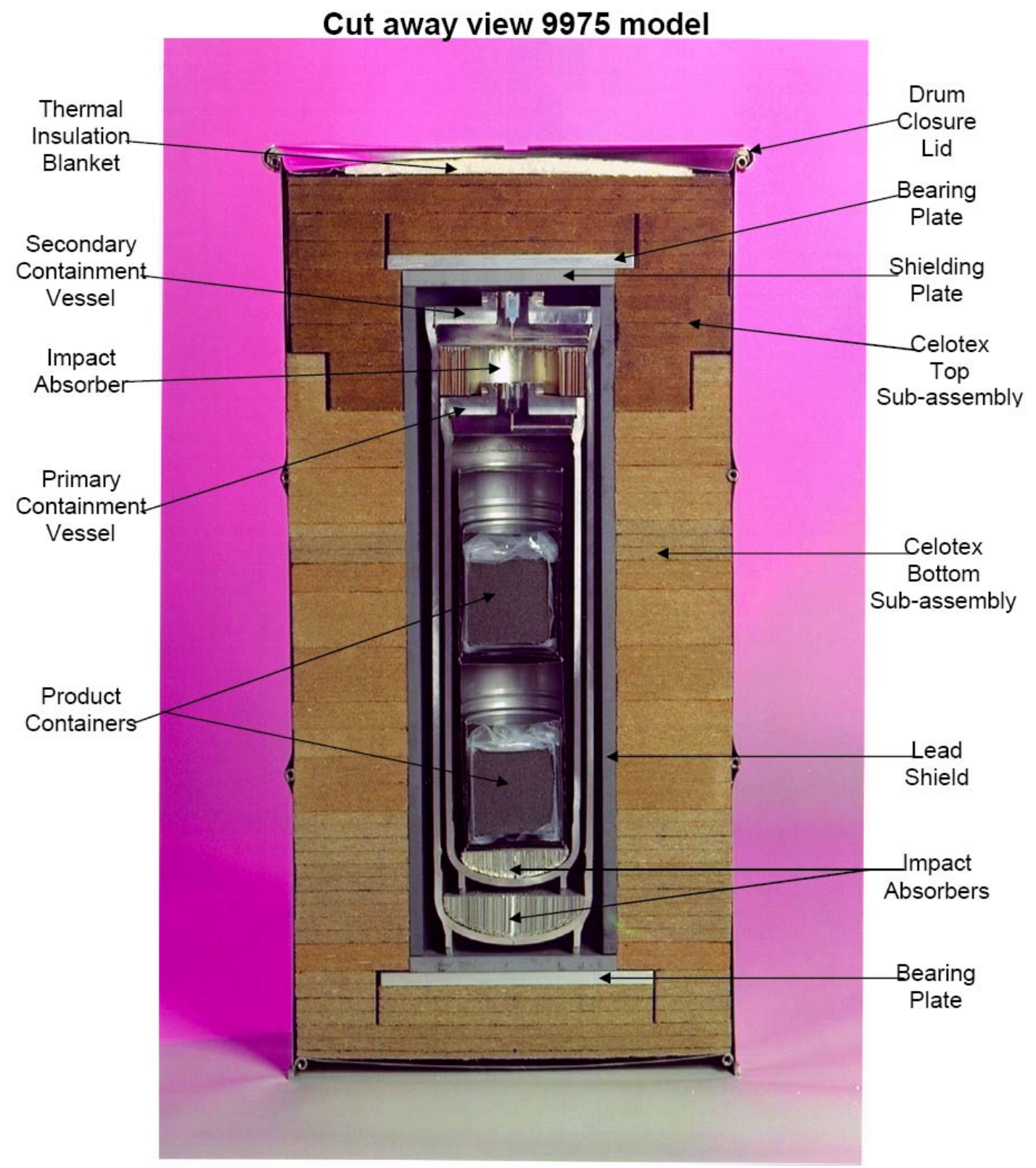

Figure 1. Model 9975 Packaging and Components 


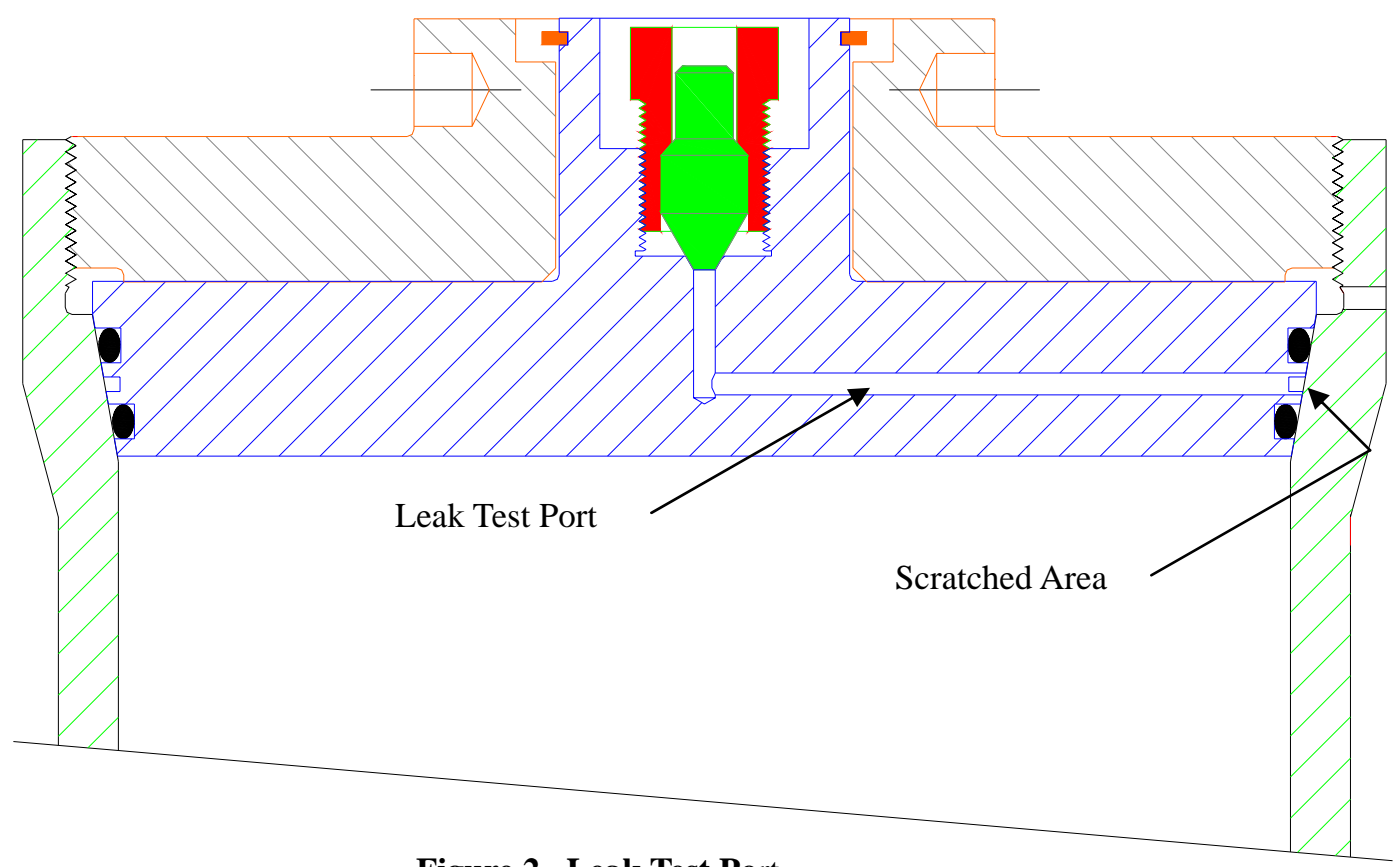

Figure 2. Leak Test Port

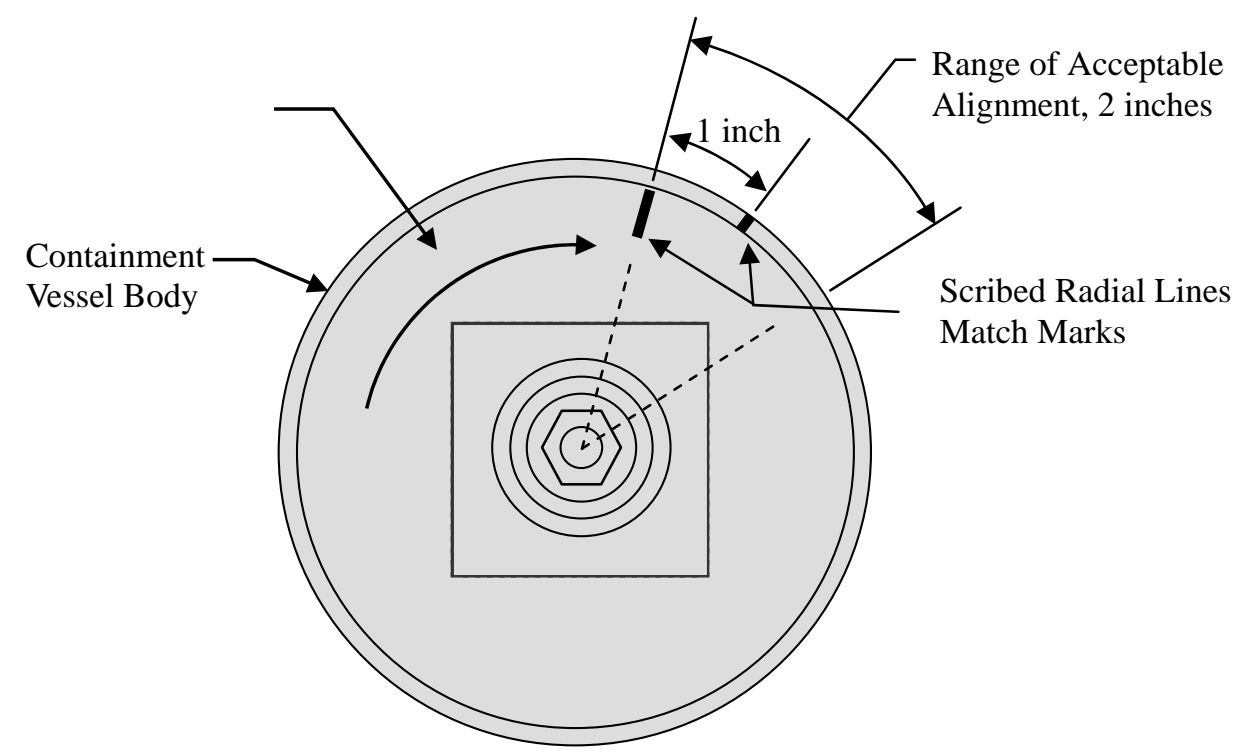

Figure 3. CV alignment marks 